JAROSŁAW GARA

Wydział Nauk Pedagogicznych

Forum Pedagogiczne

9 (2019) 2, cz. 2

Akademia Pedagogiki Specjalnej im. M. Grzegorzewskiej

Wpłynęło: 13.12 .2018

Warszawa

ORCID ID: https://orcid.org/oooo-0oo1-6251-5972

\title{
MIĘDZY IDEALIZACJĄ A MISTYFIKACJĄ - PEDAGOGICZNY CASUS DIALOGICZNEGO ZAGADYWANIA I ODPOWIADANIA
}

\begin{abstract}
„Znaczenie każdej ludzkiej sytuacji jest tej sytuacji immanentne, jest ona bowiem zarazem jego rozumieniem i spełnieniem"
\end{abstract}

(Levinas 2008, s. 55).

„Symbol zawsze przerasta tego, kto symbolu używa, i zmusza go, by mówił więcej niż sądzi, że mówi"

(Camus 1991, s. 113).

Streszczenie: Tytułowy problem ujęty został w kontekście odróżnienia od siebie pięciu podstawowych sposobów rozumienia dialogu. Zgodnie z przyjętym modelem dialogu, jako aktu spotkania, kluczowym medium relacji międzyludzkiej, w tym relacji pedagogicznej, jest fenomen zagadywania i odpowiadania. Tak rozumiany dialog wyrasta z określonych założeń, co do rozumienia samego człowieka, zgodnie z którymi człowiek jako jednostka nie tylko jest odrębnym światem, lecz także tworzy odrębne światy. Dialog staje się zatem możliwy tylko między podmiotami, które wzajemnie uznają swą odrębność oraz podejmują autentyczny wysiłek wykraczania ku innemu człowiekowi. Rzeczywisty dialog należy również zdecydowanie odróżnić od różnych negatywnych stanów rzeczy, które są antywzorcami dialogicznego zagadywania i odpowiadania. Dlatego też ujęcie racji i nastawień sprzecznych z racjami i nastawieniami dialogu pozwala lepiej zrozumieć konstruktywny sens oraz niecodzienność fenomenu dialogu.

Słowa kluczowe: filozofia dialogu; filozofia wychowania; dialogika wychowania; dialog jako spotkanie; relacja pedagogiczna; negatywne stany rzeczy. 


\section{Przyjęta perspektywa poznawcza i towarzyszące jej założenia}

Tytułowa formuła ${ }^{1}$ odsyła nas do przedmiotu zainteresowania, który ujmuję z perspektyw szeroko rozumianej filozofii wychowania. Samą filozofię wychowania w jej podstawowych zadaniach i funkcjach pojmuję zaś jako taką perspektywę poznawczą, w obrębie której stawiane są pytania o kwestie najbardziej prymarne, stojące u podstaw sensów i znaczeń myślenia i działania pedagogicznego. Owe kwestie prymarne zawsze też związane są z określonymi rozstrzygnięciami ontologicznymi, epistemologicznymi czy metodologicznymi, oraz ich konsekwencjami dla teoretycznych lub praktycznych wymiarów myślenia i działania pedagogicznego (Benner 2015, s. 13, Kron 2012, s. 22; Rybák 2014, s. 42; 2017, s. 69).

Od strony poznawczych zorientowań i związanych z tym tradycji intelektualnych tak dookreślana problematyka lokuje się na pograniczu dyskursu fenomenologicznego, egzystencjalnego i hermeneutycznego. Dialogika, a zatem filozofia dialogu, może być bowiem rozpatrywana z perspektywy przenikania się (w pewnych zakresach problemowych i koncepcyjnych) oraz komplementarności (z równoczesnym uwzględnieniem różnic w określonych kwestiach) tych trzech perspektyw poznawczych. W tym też kontekście postaram się zaproponować pewną drogę rozumowania $^{2}$ oraz wskazać określone założenia, przesłanki i tropy, które drogę tę w jej autorskim ujęciu czynią konsekwentną, pozwalając tym samym rozjaśnić wewnętrzną strukturę tytułowego problematu.

\section{Kategoria dialogu i jej koncepcyjne reprezentacje}

Tadeusz Gadacz w swoich studiach z zakresu filozofii XX wieku wyróżnił pięć najważniejszych konceptualizacji kategorii dialogu, które można uznać za reprezentatywne dla próby porządkowania podstawowych sposobów obecności tejże kategorii w określonych kontekstach problemowych i dyscyplinarnych dyskursach. Mowa tu zatem o dialogu rozumianym jako: 1. akt dyskursywnej komunikacji (w ramach teorii krytycznej: Jürgen Habermas), 2. akt „gościnności użyczanej przez mowę" (w ramach filozofii hermeneutycznej: Paul Ricoeur), 3. akt spotkania (w ramach filozofii dialogu: Franz Rosenzweig, Martin Buber, Emmanuel Levinas i inni), 4 akt społeczny (w ramach filozofii życia: Georg Simmel), 5. akt wydarzenia się prawdy (w ramach filozofii hermeneutycznej: Hans Georg Gadamer) ${ }^{3}$.

1 Artykuł ten jest zapisem odczytu, wygłoszonego na forum Zespołu Teorii Wychowania PAN w dniu 23 kwietnia 2018 roku w Warszawie.

2 W myśl źródłowego znaczenia pojęcie methodos (gr. meta - „wzdłuż”; odos - „droga”) oznacza poprawne/właściwe chodzenie-wzdłuż-drogi (Bocheński 1993, s. 20-21).

3 Kolejność powyższych konceptualizacji dialogu przywołuję zgodnie z porządkującym układem, jaki w omawianiu tych stanowisk zastosował autor (Gadacz 2015). 


\section{Ad. 1. Dialog jako akt dyskursywnej komunikacji}

Dialog określony jest tu dwoma warunkami: „posługiwaniem się tym samym językiem” i uczestnictwem w tym samym „polu komunikacyjnej racjonalności”. Tak rozumiany dialog jest też częścią teorii działania komunikacyjnego, która odnosi się do mechanizmów demokracji i współczesnych form życia społecznego. Tak więc dialog to komunikacja, w której kluczową rolę na drodze wypracowywania konsensusu i porozumienia - w obliczu różnych „sfer życia praktycznego i interesów społecznych" - odgrywa język. Komunikacja polega na językowym dochodzeniu do porozumienia i zgody ze względu na określone roszczenia, wysuwane przez poszczególne strony życia społecznego. Warunkiem sensowności takiej komunikacji jest zapewnienie warunków jej intersubiektywności, dlatego też kategoria intersubiektywności odgrywa tu szczególną rolę. Tylko w ten sposób komunikacja może służyć swojemu podstawowemu celowi, czyli porozumieniu „Co do czegoś” oraz wzajemnemu zrozumieniu stanowisk poszczególnych stron, reprezentujących określone interesy czy roszczenia. Społeczne formy komunikacji służą uzgodnieniu treści wypowiedzi i ich akceptacji. Wypracowywanie językowego porozumienia nie jest aktem spontanicznym, czy też eksponującym wymiar personalny (osobowy), tak jak ujmowane jest to w filozofii dialogu. Porozumienie powinno być bowiem w sposób metodyczny projektowane/konstruowane w ramach systemu wypracowanych i wdrażanych działań, które mają charakter skoordynowany (Gadacz 2015, s. 77-78).

\section{Ad. 2. Dialog jako akt „gościnności użyczanej przez mowe”}

W tym ujęciu dialog polega na „otwartości na rozumienie”, tak iż mówimy o takim jego znaczeniu, które wykracza poza racjonalne funkcje „komunikacyjnego konsensu i kompromisu”. Dialogowa „otwartość na rozumienie” wyrażona zostaje tu poprzez odwołanie do tytułowej metafory językowego przekładu: „gościnności użyczanej przez mowę". Metafora przekładu tekstu odsyła nas bowiem do pojmowania samego przekładu jako aktu duchowego, dzięki któremu tłumacz jest zdolny do wniknięcia w system językowych znaków i pojęć, na których oparty jest przekaz i narracja owego tekstu. To „przeniesienie się” tłumacza w świat cudzego języka, by go zrozumieć i odczytać, jest też podobne do tego, gdy u kogoś gościmy na warunkach jego własnego domostwa. A potem zapraszamy owego gospodarza ponownie do własnego domu, własnego świata językowych znaków i pojęć, przy pomocy których my sami udzielamy mu gościny w swojej mowie. „Otwartość na rozumienie”, która wydarza się w „gościnności użyczanej przez mowę” odsyła nas tym samym do takiego modelu dialogu, którego zastosowanie jest trudno mierzalne i nie poddaje się prostej operacjonalizacji. To dialog, który wyrzeka się redukowania „perspektywy kulturowej i egzystencjalnej innego/innych” do własnych immamentnych perspektyw. Dialog jako „otwartość na rozumienie” to gotowość do przyjęcia zaproszenia ze strony innego, aby doświadczać relacji z nim z jego własnej perspektywy. Warunkami brzegowymi takiego dialogu jest właściwa 
konstytucja tożsamości człowieka: nie może ona być ani kostyczna (dogmatyczna w swym osobowym rdzeniu), ani rozmyta (wyjałowiona w swym osobowym rdzeniu) (Gadacz 2015, s. 79-81).

\section{Ad. 3. Dialog jako akt spotkania}

Dialog jako spotkanie ma charakter egzystencjalny, rozgrywa się między osobami i jest autentycznym, niepowtarzalnym wydarzeniem, które nie może być socjotechnicznie zainscenizowane lub wyreżyserowane. Osobowy wymiar Ja i Ty wyłania się tylko we wzajemnej relacji, choć zarazem między Ja i Ty istnieje nieredukowalna różnica i odrębność. Relacja nie jest więc miejscem niwelowania lub scalania, ale uwidaczniania różnicy i odrębności (indywidualności) Ja i Ty. Dialog jako spotkanie jest darem własnej obecności oraz afirmacją innej osoby. Dialog wydarza się w spotkaniu i mowie, które zawsze są „darem obecności”. Obecność zaś to coś więcej niż fizykalność, a mowa to coś więcej niż znaczenia. Spotkanie osób jest bezpośredniością i teraźniejszością, wydarza się hic et nunc pomiędzy Ja i Ty, a każdy element pośredniczący jest przeszkodą. To, co wydarza się w spotkaniu, jest relacją Ja i Ty, nie poddaje się więc obiektywizacji oraz jest niekomunikowalne i nieprzekładalne na język uprzedmiatawiającej wiedzy. W dialogu jako akcie spotkania mowa jest zawsze relacją z drugą osobą, jest zagadywaniem lub odpowiadaniem, ponieważ mówić/rozmawiać „o”, oznacza już mówić/rozmawiać o „To”, tematyzować i uprzedmiatawiać drugiego człowieka. Dialog jest więc wykraczaniem ku innej osobie, a osoba jest niepowtarzalna i odrębna, i dlatego wymaga, aby być przyjętą w swej inności i różnicy. Drugi człowiek nie może być zatem traktowany - wprost lub pośrednio - jako nasze własne alter ego. Z tego też względu autentyczne wydarzanie się dialogu jako osobowego spotkania jest czymś wyjątkowym i niecodziennym, co wpływa na bieg życia człowieka, który go doświadcza i w nim uczestniczy (Gadacz 2015, s. 81-84).

\section{Ad. 4. Dialog jako akt społeczny}

Dialog jako akt społeczny oparty jest na założeniu, że życie jednostek określane jest relacjami społecznymi i powinno być wyrażane w języku apriorycznych praw relacji społecznych. Choć osobowe Ty jest niezaprzeczalną realnością, to jednak nie można posiąść wiedzy o cudzym indywiduum i jego „głęboko ukrytych punktach indywidualności”, ponieważ cudzej indywidualności nie można „wewnętrznie otworzyć”. Dlatego też to role społeczne, przybierając postać schematu „ja-on/ona/ ono" stają się medium dialogu jako aktu społecznego. W ten sposób role społeczne ukazują byt jednostkowy w świetle tego, co ogólne. Role społeczne jako uogólnienie bytu jednostkowego umożliwiają zaistnienie samego społeczeństwa i relacji społecznych. W ten sposób jednostka zawsze może zostać przyporządkowana do jakiejś czytelnej i rozpoznawalnej społecznie kategorii ogólnej, takiej jak: uczeń, rodzic, student czy wojskowy, a samo uogólnienie jest zarazem czymś, co stanowi „przesłonę indywidualności i jej odsłonę”. Relacje społeczne umożliwiają więc 
urzeczywistnianie się tego, co wspólne, a medium tego, co wspólne, są społecznie pełnione role. Indywidualność człowieka w relacjach społecznych i za pośrednictwem medium ról społecznych nie tylko jest skryta w swym uogólnieniu, ale również poprzez wchodzenie w odmienne role, na inny sposób uwidacznia sama siebie w odmiennie definiowanych obszarach społecznie pełnionych ról (Gadacz 2015, s. 84-85).

\section{Ad. 5. Dialog jako akt wydarzenia się prawdy}

W tym ujęciu kluczową rolę przypisuje się kategorii Augustiańskiej idei „wewnętrznego słowa" (verbum interius), z której wyrasta przyjmowana koncepcja języka. "Jedność wewnętrznego słowa" (Logos) nie jest zaś tym, co człowiek posiada, ale tym, co człowieka prowadzi i ma w posiadaniu. Język jest „źródłem i warunkiem możliwości słowa i myśli". Świadomość ludzka nigdy bowiem nie jest odseparowana od języka, ale jest „ogarnięta przez język”, a sam Logos wyłania się/odsłania się w rozmowie. Dzięki językowi dokonuje się transmisja „duchowego wpływu, jaki następuje w trakcie myślenia, mówienia-siebie”. „Duchowy wymiar” jest też tym, ze względu na co słowo jest żywe i posiada zdolność, aby „dosięgać, uderzać, poruszać”. Przynależność człowieka do „wspólnoty rozmowy” pozwala mu też wyrwać się z swojej własnej skończoności i jest odpowiedzią na konsty tutywną „niemożność samopoznania” oraz „osiągnięcia samopewności”. Owa przynależność tworzy więc warunki, aby człowiek w ogóle rozumiał język, innego człowieka oraz samego siebie. Ta koncepcja dialogu nawiązuje zatem zarówno do modelu dialogu jako aktu komunikacyjnego, jak i dialogu jako aktu spotkania, choć w tym drugim przypadku unieważnione zostają takie kluczowe dla filozofii dialogu przesłanki, jak: uznanie nieredukowalnej podmiotowej różnicy pomiędzy Ja i Ty oraz uznanie całkowitej niedookreśloności wydarzania się autentycznego dialogu. Z koncepcją dialogu jako aktu spotkania nie sposób również pogodzić tych założeń, zgodnie z którymi: 1. dialog w sposób uprzedni może być określany przez ostateczną znajomość ,„jedności i całości”, 2. miarą dialogu może lub powinien być wzorzec „dialogów sokratejskich” (Gadacz 2015, s. 85-88).

Przywołane konceptualizacje dialogu, obecne w myśli filozoficznej XX wieku, pokazują, w jak różny sposób problematyka ta może być dookreślana i do jak różnej proweniencji źródeł oraz zakresów znaczeniowych może nas odsyłać filozoficznie wywodzona i problematyzowana kategoria dialogu. Na dużym pułapie ogólności zrekonstruowane modele dialogu można traktować jako różne sposoby naświetlania wspólnego i szeroko rozumianego obszaru problemowego. Niemniej jednak rozpatrując owe konceptualizacje w wyższej rozdzielczości i bardziej analitycznie, trudno nie zauważyć też odmiennych kontekstów teoriopoznawczych i związanych z tym założeń i konsekwencji. Nie sposób oprzeć się również pewnej refleksji, że obecność kategorii dialogu w szeroko rozumianej pedagogicznej literaturze przedmiotu rzadko kiedy odsyła nas do jednoznacznie wydzielanych zakresów znaczeniowych w ich koncepcyjnych usytuowaniach i odniesieniach. Uznając więc 
zasadność powyższych dystynkcji, związanych z obecnością podstawowych modeli dialogu w myśli filozoficznej XX wieku, ich specyficznych akcentów i założeń poznawczych, podejmowany przeze mnie problem zasadniczo związany będzie z trzecim znaczeniem dialogu, a zatem dialogu jako aktu spotkania, reprezentatywnego dla filozofii dialogu. Nie zmienia to jednak faktu, że sposób ujmowania niektórych zagadnień będzie również bliski kontekstom problemowym, które określają modele dialogu jako aktu „gościnności użyczanej przez mowę” oraz aktu wydarzania się prawdy.

\section{Prymarne przesłanki i pryncypia dialogicznych nastawień poznawczych oraz racji działania}

Na wstępie można postawić tyleż prymarne, co i banalne na pierwszy rzut oka pytanie: Dlaczego w ogóle dialog jest czymś ważnym i potrzebnym? Czy dlatego, że wszyscy jesteśmy tacy sami: chcemy tego samego, kierujemy się tym samym, myślimy tak samo, uznajemy za słuszne to samo, dążymy do tego samego czy też cenimy to samo? Otóż nie. Paradoksalnie, to właśnie różne odruchowe (instynktowne) i potocznie podtrzymywane mniemania dotyczące tej kwestii i związanych z nią rozstrzygnięć są źródłem zarówno idealizacyjnego, jak i mistyfikacyjnego ujmowania w świecie życia codziennego implicytnych sensów i znaczeń kategorii dialogu.

Egzystencjalna nieredukowalność dialogu w świecie ludzkich spraw jest wyrazem rudymentarnego faktu, który określa kondycję ludzką, tego mianowicie, że nigdy nie jesteśmy tacy sami (Gadacz 2015, s. 75). Zazwyczaj nie chcemy tego samego, nie kierujemy się tym samym, nie myślimy tak samo, nie uznajemy tego samego, nie dążymy do tego samego i nie cenimy tych samych rzeczy. Co więcej, to właśnie jednostkowa, nieredukowalna odrębność jest konstytutywnym elementem poświadczającym ludzką podmiotowość. Podmiotowość to odrębność, przybierająca postać zdolności do pełnomocnych aktów, wyrażających się w autonomii tego, co jest przedmiotem chcenia, kierowania się, myślenia, uznawania, dążenia czy cenienia.

Dialog nie polega więc na tym, by w sposób mniej lub bardziej subtelny skłonić, przekonać, uwarunkować, przechytrzyć (poddać bezpośredniej lub pośredniej kolonizacji) innych ludzi, tak, by się do nas upodobnili i nie odróżniali się od nas w aktach swojego chcenia, kierowania się, myślenia, uznawania, dążenia czy cenienia.

W tym kontekście należy sformułować cztery prymarne założenia, odnoszące się do dialogicznej kondycji człowieka:

1. Człowiek jest określany własnym podmiotowo nieredukowalnym istnieniem; jest bytem odrębnym i zamkniętym w sobie samym (ma własne myśli, pragnienia, odczucia, potrzeby, aspiracje); jest sobością, w pierwszym 
rzędzie określaną własnymi egzystencjalnymi trajektoriami i sposobami przeżywania otaczającego świata ${ }^{4}$;

2. Człowiek jest nie tylko odrębnym/odmiennym światem („mikrokosmosem”), lecz także podziela/uznaje lub tworzy odrębne światy (uzasadnień, ideałów, aspiracji, odniesień, rang). W obrębie tych odmiennych światów zakorzenia się i czyni je punktami orientacyjnymi swojego podmiotowego istnienia i swej tożsamości ${ }^{5}$.

3. Tylko człowiek, który autentycznie doświadcza własnej podmiotowości, może w sposób faktyczny wykraczać ku innemu człowiekowi w akcie dialogowego spotkania. Autentyczna relacja nie polega bowiem na znoszeniu odrębności i dystansu, ale na przerzucaniu pomostów, które pozwalają oswajać się z podmiotową odrębnością i przemierzać dystans dzielący określone podmioty relacji.

4. Dialogiczne uznanie nieredukowalności podmiotowej odrębności i podmiotowego dystansu, wymaga aktywnej woli i autentycznego wysiłku każdego z podmiotów, tak aby dialogowe spotkanie mogło się stać czymś rzeczywistym. Dialog nie wydarza się więc sam z siebie, niezawodnie i raz na zawsze, ponieważ zawsze jest pochodną obopólnej woli i wysiłku podmiotów na drodze oswajania, a nie uniformizującego neutralizowania odrębności oraz przemierzania, a nie deprecjonującego znoszenia dystansu'.

\section{Problemowe konteksty casusu dialogicznego zagadywania i odpowiadania}

W ramach trzeciej z wyróżnionych konceptualizacji dialogu - dialogu jako spotkania należy wskazać na zasadniczą dystynkcję, podkreślaną lub obecną na różne sposoby w filozoficznych projektach tworzonych przez filozofów dialogu. Otóż przedmiotem tej dystynkcji jest nieredukowalne odróżnienie od siebie dwóch antynomicznych tradycji intelektualnych oraz ich konsekwencji teoriopoznawczych. Tradycje te umownie można nazwać kultura starożytnej ontologii grecko-rzymskiej

4 „Pogłębienie mojej własnej tożsamości - stwierdza Barbara Skarga, odnosząc się do filozoficznego projektu E. Levinasa - staje się więc pierwszym warunkiem uznania inności innego, tego, który nie może być ze mną tożsamy, którego nie mogę włączyć w krąg mego świata, który pozostaje zawsze poza, nieobjęty, niezrozumiały, z kim mogę nawiązać kontakt, choć ten kontakt nie daje się ująć w żadnych kategoriach logicznych" (1992, s. 59).

5 Ludzkie „wnętrze - konstatuje M. Buber w swojej filozofii wychowania - stanowi pierwotnie polifonię, w której żadnego głosu nie da się zredukować do innego, a jedności niepodobna uchwycić analitycznie" (1968, s. 445; zob. także: Glinkowski 2016, s. 37-50).

6 „Kontaktu z drugim nie nawiązuje się, gdy razem jesteśmy w topieni w jakąś całość, gdyż bycie całości zaciera różnice [...]. Skupienie w sobie nie zamyka wrażliwości na to, co zewnątrz mnie, przeciwnie, w bycie separowanym istnieje szczelina, otwarcie pozwalająca przyjąć innego. Spotkanie z drugim nie jest negacją separacji” (Skarga 1992, s. 59). 
oraz kulturą starożytnej ontologii hebrajskiej $j^{7}$. E. Levinas posługuje się w tym kontekście m.in. takimi określeniami, jak: kultura immanencji versus kultura transcendencji, kultura wiedzy i techniki versus kultura etyczna (relacji) (1984, s. 28, 32; 34) oraz humanizm hebrajski vesus humanizm helleński (1991b, s. 293, 296; zob. także: 1991a; Rogóż 2011). W kontekście logiki takich przeciwstawień Abraham Joshua Heschel (2007, s. 23) stwierdza dobitnie: „Myśl hebrajska operuje kategoriami odmiennymi od platońskich czy arystotelesowskich, a odrębność właściwego dla niej nauczania nie jest kwestią innego sposobu wyrażania się, lecz odmiennego sposobu myślenia. [...] Geograficznie i historycznie Ateny i Jeruzalem, wiek profetów i wiek Peryklesa, nie pozostają od siebie zbyt odległe. Lecz duchowo to światy odrębne".

Kultura immanencji wyraża się w roszczeniu totalności/całości, „gdzie Inny zostaje pozbawiony swej inności, gdzie staje się on treścią mojej wiedzy, jego transcendencja - moją immanencją" (Levinas 1984, s. 28). Kultura immanencji afirmuje to, co pozwala zredukować wszelką odmienność/odrębność/inność do „tych samych ogólnie obowiązujących zasad i praw; ceni ona idee ogólne, w świetle których istotne staje się to, co wspólne, co jednoczy, upodabnia" (Skarga 1992, s. 50). Kultura immanencji ma własne immanentne wzorce „dialogu”, które w rzeczywistości są nieprzezwyciężalną egzystencjalną monologicznością. Wzorcem takiego „dialogu" jako monologu, zgodnie z ujęciem filozofii dialogu, są „dialogi sokratejskie”: "Sokrates nie chce przyjmować od drugiego człowieka nic, co nie jest już obecne w nim samym”. Dlatego też taki dialog jest afirmacją tego-co-tożsame oraz neutralizacją i wchłanianiem tego, co inne, unicestwianiem różnicy pod pozorem prowadzenia dialogów (Gadacz 2015, s. 89).

W odróżnieniu od tego kultura transcendencji opiera się na bezwarunkowym respekcie dla podmiotowej jednostkowości/odrębności/różnicy. „"Myśl» obudzona ku twarzy lub przez twarz jest poddana władzy nieredukowalnej różnicy, dyferencji: to nie jest już myśl o..., lecz natychmiast myśl dla...; ta nie-in-dyferencja wobec innego narusza równowagę duszy obojętnej i niewzruszonej w poznaniu" (Levinas 1984, s. 33; por. także: Levinas 2008, s. 252). Kultura transcendencji w radykalny sposób wyrzeka się „jednostronnej tradycji greckiej” (Skarga 1984, s. 145), wyrażonej w redukcjonizmie Parmenidesa (Rosenzweig 1998, s. 65-66), zgodnie z którym „Dla mnie jest jedno i toż samo, skądkolwiek zacznę - jak zakładał ów filozof - gdyż wrócę zawsze do tego samego. [...] Pomyśleć i być jest toż samo"

7 Mowa jest tu o kulturze starożytnej ontologii grecko-rzymskiej, ponieważ świat rzymski traktowany jest jako ten, który wyrastał na gruzach świata grackiego, przejmując i adoptując dla swoich potrzeb wybrane elementy i osiągnięcia dziedzictwa greckiego. W tym też kontekście, w sposób symboliczny, stolice tych „odrębnych kulturowych światów” uzasadnień i uprawomocnień są sobie przeciwstawiane: Ateny i Rzym versus Jerozolima. Odrębność ontologicznych fundamentów owych „światów” przedmiotem swojego zainteresowania uczynił również w swych egzystencjalno-fideistycznych analizach Lew Szestow (2009). 
(Parmenides 1992, s. 40). Kultura transcendencji rozbija „jednolitość”, dającej się objąć i pomyśleć „Wszystkości” (immanencji, całości, totalności) na kawałki, rehabilitując w ten sposób różnice i odmienność (Rosenzweig 1998, s. 180). „Kultura konstatuje filozof - nie jest przezwyciężeniem ani neutralizacją transcendencji; ona tkwi w odpowiedzialności etycznej i zobowiązaniu wobec drugiego, w stosunku do transcendencji jako transcendencji” (Levinas 1984, s. 34).

Dla pierwszej tradycji intelektualnej symboliczną figurą jest mitologiczna tułaczka Odyseusza oraz wpisane w nią powroty, podstęp i walka. W przypadku drugiej tradycji symboliczną figurą jest zaś biblijna wędrówka Abrahama oraz wpisane w nią wykraczanie, poświęcenie i zawierzenie. Odyseusz we wszystkim, co robi i czego się podejmuje, ma na względzie powrót do miejsca, z którego wyruszył - do ziemi znanej, do tego, co własne (Ziemi Ojczystej), a zatem do tego-co-tożsame. Abraham we wszystkim, co robi i czego się podejmuje ma na względzie dotarcie i wkroczenie do ziemi, która jest mu obca i w zupełności nieznana (Ziemi Obiecanej), a zatem do tego-co-inne. W tym znaczeniu Odyseusz jest wędrowcem-tułaczem, który szuka drogi do Tego-Znanego, Abraham zaś jest wędrowcem-pielgrzymem, który szuka drogi do Tego-Nieznanego ${ }^{8}$.

W tym znaczeniu symboliczne trajektoria losu Odyseusza konstytuują się w obrębie pewności tego, co znane (tożsamości jako pozycjonowania się w obrębie tego-co-takie-samo) i ku temu, co znane, zawsze są zwrócone jako teleologicznego horyzontu dążeń. W odróżnieniu od tego symboliczne trajektoria losu Abrahama konstytuują się w obrębie niepewności tego, co nieznane i ku temu, co nieznane (tożsamości jako ruchu wykraczania poza obręb tego-co-takie-samo ku temu-co-Inne) zawsze są zwrócone jako teleologicznego horyzontu dążeń. Tożsamość Odyseusza określana jest antycypacją jedności i całości (totalności, która stoi na straży utrwalonego status quo). Tożsamość Abrahama określana jest zaś antycypacją różnicy i inności (transcendencji, która narusza lub wykracza poza utrwalony status quo). Odyseusz poszukuje i odnajduje drogę do Znanego, powraca do miejsca, z którego wyruszył. Abraham poszukuje i odnajduje drogę do Nieznanego, wkracza na stałe do miejsc odległych i odmiennych od tych, z których wyruszył.

Przeciwstawienie sobie symbolicznych figur wędrówki Odyseusza i Abrahama pozwala też dookreślić sensy pedagogicznego casusu dialogicznego zagadywania i odpowiadania. Owe sensy można bowiem ująć jako transpozycje symboliki wędrówki Abrahama. Dialogiczne zagadywanie i odpowiadanie zawsze odbywa się w intersubiektywnej przestrzeni styczności. Należy je też uznać za podstawowe, spersonalizowane postacie bezpośrednich form zwracania się (gest, słowo, działanie) jednego człowieka do drugiego człowieka. W zagadywaniu i odpowiadaniu dochodzi bowiem do jednego z najbardziej prymarnych aktów egzystencjalnych: odsłaniania i uobecniania siebie samego w owym zagadnięciu oraz odpowiedzi.

8 Do symbolicznej wymowy figur Odyseusza i Abrahama odwołuję się również szerzej w innym miejscu i w nieco innym kontekście (Gara 2016, s. 11-24; 2018b, s. 101-103). 
Autentyczne zagadywanie i odpowiadanie wyraża się zaś „w przychodzeniu w sukurs" sobie samemu - własnemu sposobowi bycia w relacji do drugiego człowieka, tzn. własnemu zagadywaniu i odpowiadaniu. Personalny wymiar autentyczności lub nieautentyczności, faktyczności lub upozorowania zagadywania i odpowiadania jest więc pochodną autentyczności lub nieautentyczności, faktyczności lub upozorowania „przychodzenia w sukurs” (Lévinas 2002, s. 66) własnemu zagadnięciu lub odpowiedzi. Mówiąc zaś o pedagogicznym casusie zagadywania i odpowiadania, przyjmuję założenie, zgodnie z którym podstawową strukturą aktów wychowania i kształcenia, ujmując rzecz dialogicznie, jest właśnie zagadywanie i odpowiadanie. Sednem dialogicznego zagadywania i odpowiadania jest bowiem zwracanie się do innego podmiotu jako podmiotu nieredukowalnej odrębności i różnicy.

W tym też kontekście powiemy, że dialogiczne zagadywanie i odpowiadanie:

1. Wyraża się w uobecnianiu się (zawieraniu siebie samego, darowywaniu wraz z mową cząstki siebie samego, przychodzeniu w sukurs sobie samemu) w akcie wykraczania ku innemu człowiekowi;

2. Autentyczne zagadnięcie jest gotowe na przebycie drogi, która dopiero umożliwia udzielenie odpowiedzi. Na drodze tej trzeba opuścić to, co Znane i wykroczyć ku temu, co Nieznane; przejście od tego, co Znane do tego, co Nieznane, określane jest miarami rzeczywistego dystansu;

3. Ten, kto zagaduje, wystawia się na Nieznane odpowiedzi odpowiadającego, a ten, kto odpowiada, otwiera się na zagadnięcie, które zawsze pochodzi $\mathrm{z}$ innego miejsca niż jego własne miejsce jako odpowiadającego;

4. Zagadnięcie zagadującego zawsze jest wolą naruszania własnego status quo w wychylaniu się ku horyzontowi tego, co Nieznane, a odpowiedź odpowiadającego zawsze jest w drodze - nigdy nie jest skończona/dopełniona, tak jak horyzont drogi do Ziemi Obiecanej.

5. Zagadywanie i odpowiadanie nigdy nie odbywa się w horyzoncie totalności (roszczenia zawładnięcia, wchłonięcia, podporządkowania, kolonizacji, manipulatorskiego uprzedmiotowienia) myślenia i działania. Zagadnięcie nie suponuje skrycie swoich punktów widzenia, a odpowiedź nie neutralizuje władczo autonomii zagadnięcia.

6. Zagadywanie i odpowiadanie zawsze oddzielone jest rzeczywistym dystansem tego, co Nieznane, a dialogiczne uobecnienie się nie jest znoszeniem dystansu pomiędzy zagadującym i odpowiadającym, ale pokonywaniem owego dystansu, przy jednoczesnym jego zachowaniu.

\section{Idealizacja i mistyfikacja jako problem uobecniania się w intersubiektywnej przestrzeni styczności}

Problem idealizacji (upozorowania i uwznioślenia), jak i mistyfikacji (upozorowania oraz zainscenizowania) w kontekście dialogicznej kategorii zagadywania i odpowiadania odsyła nas do kwestii nierzeczywistego/nieautentycznego lub 
niepełnego (wypreparowanego antropotechnicznie, socjotechnicznie lub kulturotechnicznie) uobecniania się w interpersonalnej przestrzeni styczności - przestrzeni spotkania pomiędzy podmiotami relacji, Ja i Ty. Idealizacja i mistyfikacja w tej samej mierze stanowi bowiem o nierzeczywistych/nieautentycznych postaciach spotkania w interpersonalnej przestrzeni styczności. Autentyczne uobecnianie się w interpersonalnej przestrzeni styczności zawsze stoi bowiem w nieredukowalnej opozycji do wyreżyserowanych i zainscenizowanych postaci bycia, które można określić mianem „ludzi z kryjówek” jako ludzi „ciasnej przestrzeni” (Tischner 2002, s. 412-414), graczy/aktorów „historycznego kamuflażu”, promujących „fałszywą postać życia” (Gasset 1995, s. 141, 189), „ludzi zza kulis” czy też kodyfikatorów i operatorów fasadowych „rytuałów interakcyjnych” (Goffman 2008, s. 135-167; Goffman 2012).

Idąc tak dookreślanymi tropami rozumowania w sposób autorski wyróżniam następujące negatywne stany rzeczy ${ }^{9}$ (antywzorce), które są całkowitym zaprzeczeniem dialogicznego zagadywania i odpowiadania, w postaci:

1. dwóch zasadniczych postaci mistyfikacji „ludzi z kryjówek”/,ludzi zza kulis”;

2. trzech zasadniczych personifikacji gracza jako aktora "historycznego kamuflażu”.

\section{Ad. 1)}

\section{a) mistyfikacja jako maskowanie i retuszowanie pustki}

Zjawisko mistyfikacji czynu jako maskowanie i retuszowanie pustki polega na próbie zakrycia tego, co wyraża się w nieuobecnianiu się podmiotu czynu w samym czynie. Chodzi tu zatem o próby zasłaniania (utajania), związane z wysiłkami, aby inni mogli widzieć tylko to, co nie stanowi zagrożenia dla zdemaskowania naszych czynów pustych (fasadowych). Zakrycie i zasłonięcie tego, co jest niewygodne, to metoda kształtowania opinii innych/opinii publicznej - „wiary”/wyobrażeń innych w intencjonalnie kreowany przez nas publiczny wizerunek nas samych. To, do czego inni mają dostęp, opiera się więc na zewnętrznie zawężonym lub intencjonalnie wyreżyserowanym polu percepcji określonych rzeczy. Mistyfikator pustki zawsze posługuje się strategią utajania, skrywania, zaprzeczania istnieniu określonych stanów rzeczy w tej postaci, w jakiej faktycznie zachodzą i wydarzają się.

\section{b) mistyfikacja jako upozorowanie i inscenizacja pełni}

Zjawisko mistyfikacji czynu jako upozorowanie i inscenizowanie pełni wyraża się $\mathrm{w}$ aktach przedstawiania i sugerowania istnienia tego, co w rzeczywistości nie istnieje lub nie istnieje w takiej postaci, jak jest to przedstawiane. Upozorowanie

9 Wyróżnione negatywne stany rzeczy obszerniej czynię przedmiotem swojego zainteresowania w innym miejscu. Tutaj ograniczam się tylko do reasumpcji wypracowanych tam ustaleń, a zatem zwięzłej charakterystyki: 1. postaci mistyfikacji (Gara 2017) oraz 2. personifikacji gracza (Gara 2018a). 
i inscenizowanie pełni jest zatem jakąś formą intencjonalnego wywoływania złudnych wyobrażeń lub koloryzowania (idealizowania) rzeczywistości, która jest przedmiotem zabiegów idealizacyjnych lub mistyfikacyjnych, tzn. jest próbą dodawania do rzeczywistości tego, czego rzeczywistość ta sama z siebie nie zawiera. Mistyfikator pełni zawsze chce, aby inni ulegli złudzeniu i sugestii, że to, z czym się stykają, jest czymś więcej niż to, czym określone rzeczy lub stany rzeczy w rzeczywistości ukazują się nam w naszym bezpośrednim doświadczeniu.

\section{Ad. 2)}

\section{a) personifikacja sofisty jako aktora „historycznego kamuflażu”}

Za uosobienie racji, postaw i nastawień sofisty oraz jego form ekspresji, sprawności i sprawczości można uznać Gorgiasza z Leontinoj (ok. 483-375 p.n.e.). „Magia” sprawczości sofisty opiera się na umiejętności demagogicznego argumentowania i dowodzenia, które traktowane są jako środki służące do wywierania wpływu na innych ludzi i zdobywania nad nimi przewagi, tak aby osiągać w sposób instrumentalny zakładany cel. Zgodnie z tym podejściem nie ma żadnych zasad i norm etycznych, „są tylko słowa-mocarze”, które dają erystyczną władzę, tak aby swą sugestią (psychagogia) wywierać wpływ na drugiego człowieka w „urabianiu jego poglądów, postaw i postępowania" (Legowicz 1986, s. 132).

\section{b) personifikacja cynika jako aktora „historycznego kamuflażu”}

Za uosobienie cynika można uznać Diogenesa z Synopy (ok. 412-323 p.n.e.). Diogenes sam zwykł przyrównywać się do psa (Diogenes Laertios 1988, s. 327, 342) i określany jest też „psem mądrości”. Zapytany zaś, co takiego robi, że inni nazywają go psem, odpowiedział: „Schlebiam tym, którzy mi coś dają, obszczekuję tych, którzy mi nic nie dają, a złych gryzę" (Diogenes Laertios 1988, s. 342). Zgodnie z tym wzorcem osobowym cynik zakłada, że pomimo oporu ludzi należy ich przymuszać do głoszonych przez siebie instrumentalnych zasad, wywołując w innych zawstydzenie lub konfuzję, ignorując zarazem opinię publiczną i odczucia innych ludzi.

\section{c) personifikacja socjotechnika jako aktora „historycznego kamuflażu”}

Za uosobienie socjotechnika można uznać Niccolò Machiavelliego (1469-1527). Naczelną zasadą jest tu skuteczność działań w zdobywaniu lub zabezpieczaniu władzy poprzez instytucjonalizację zdobywania przewagi. Służy temu wykorzystywanie prawa (społecznie/instytucjonalnie legitymizowanych kodyfikacji) oraz aparatu siły (społecznie/instytucjonalnie legitymizowanej przemocy). Machiavelli zalecał więc metodyczne posługiwanie się podstępem, manipulacją i wiarołomstwem tak, aby wykorzystać lojalność lojalnych, „usidlać mózgi ludzkie” i wziąć „przewage nad tymi, którzy zaufali” władcy/władzy (Machiavelli 1987, s. 86). Pomocnym instrumentem w tak sprawowanej władzy jest zaś wyzyskiwanie konfliktów i walki/ 
wojny (Szacki 2002, s. 51-52) oraz manipulatorskie posługiwanie się religią i ludzką wrażliwością religijną (Machiavelli 1987, s. 88).

\section{Dialogowa relacja „wychowawczego obejmowania” a problem idealizacji i mistyfikacji}

Zasadnicze problemy, które implikowane są przez podjęte w tym miejscu zagadnienia, można zatem wyrazić w następujących kwestiach, ukazujących dalsze, otwarte obszary problematyzacji i zmuszających namysłu:

1. Na ile pozorowanie/inscenizowane dialogu dekonstruuje/dekomponuje samą możliwość wydarzania się dialogu w różnych obszarach społeczno-kulturowej praxis, komplikując lub w ogóle uniemożliwiając realizację idei dialogu w jej różnych przejawach i postaciach?

2. Na ile idealizacje i mistyfikacje myślenia i działania w poszczególnych obszarach społeczno-kulturowej praxis oddalają lub alienują nas od możliwości konstytuowania się autentycznej intersubiektywnej przestrzeni styczności oraz wydarzającego się w nim spotkania jako specyficznie ludzkiego fenomenu, który jest fundamentem (substratem) jakościowych wymiarów „świata ludzkich spraw”?

Jednym z podstawowych w swym zadaniach i funkcjach obszarów społeczno-kulturowej praxis są szeroko rozumiane relacje pedagogiczne, zachodzące w ramach procesów wychowania i kształcenia. Z tego punktu widzenia, problemy, które w tym miejscu zostały skonstatowane, jak i zasygnalizowane, należy odnosić do mikrospołecznego wymiaru relacji międzyludzkich. Należy bowiem przyjąć, że jednym z konstytutywnych momentów (rysów, aspektów) urzeczywistniania się autentycznych relacji pedagogicznych jest relacja dialogu w rozumieniu filozofii dialogu (dialogu jako spotkania) (Kron 2012, s. 181-182). W tak rozumianej relacji pedagogicznej jako relacji dialogu należy zaś wyartykułować specyficzne racje/nastawienia, wpływające na przebieg procesów wychowania i kształcenia (Rybák 2016, s. 334). Racje te, zgodnie z myślą Martina Bubera, można określić mianem „aktów obejmowania”. Obejmowanie jako dialogiczny stosunek wychowawczy wyraża się zaś w tym, że wychowujący jest zdolny do uobecnienia siebie samego w relacji pedagogicznej, przeżywania (wczucia) świata dziecka od jego własnej strony jako bytu osobowego. Owo obejmowanie oznacza więc nie tylko „wydłużenie własnej konkretności” uobecnienia się wychowującego, lecz także - jak metaforycznie ujmuje to filozof wychowania - „wślizgnięcie się poprzez własne uczucie w dynamiczną strukturę podmiotu” wychowania (Buber 1968, s. 455), żeby „zasymilować obecność dziecka w swój własny organizm” (Buber 1968, s. 457).

$\mathrm{W}$ relacji dialogu, wyrażającego się w wychowawczym stosunku uobecniania siebie $\mathrm{w}$ relacji pedagogicznej oraz $\mathrm{w}$ wychowawczym obejmowaniu podmiotu wychowania, nie ma miejsca ani na idealizację, ani na mistyfikację. Zarówno idealizacja, jak i mistyfikacja - w różnych swych postaciach - „wdzierając się” 
w relacje pedagogiczne, deformują lub blokują wydarzanie się autentycznej relacji dialogu. Relacja dialogu jako aktu spotkania opiera się bowiem na rzeczywistej egzystencjalnej otwartości, która zawsze jest przezwyciężeniem i negacją pozoru. „Wtargnięcie pozoru” okalecza lub niweczy dialog (Buber 1992, s. 152). A przecież sednem różnych postaci idealizacji i mistyfikacji jest tworzenie, podtrzymywanie lub legitymizowanie pozorów (fikcji, ułudy, fabrykowania, manipulacji, fałszu jako sposobów zawładnięcia, neutralizacji lub pozycjonowania własnego status quo w relacji do drugiego człowieka) istnienia/zachodzenia lub nieistnienia/niezachodzenia określonych stanów rzeczy.

W obliczu powszechności idealizacyjnego lub mistyfikacyjnego fabrykowania rzeczywistości w świecie życia codziennego tak rozumiany dialog jest zatem wydarzeniem niecodziennym, tzn. nieczęstym i wymagającym nieustannej egzystencjalnej aktualizacji. Nie można go zagwarantować lub zadekretować formalnie pustymi gestami i słowami, ponieważ dialog jako zagadywanie i odpowiadanie w sposób rzeczywisty musi się wydarzać. Wydarzanie się dialogu w jego egzystencjalnej faktyczności można więc zobrazować metaforą żeglarza na pełnym oceanie, który często wiele dni, miesięcy lub lat przemierza swą morską drogę, nim na jego horyzoncie wyłoni się jakiś ląd. A przecież pomimo tej niecodzienności zmiany horyzontu, nie każdy ląd ostatecznie okazuje się właściwą i niezawodną przystanią na nieprzewidywalnej i niepewnej drodze żeglarza.

\section{Bibliografia}

Benner D. (2015). Pedagogika ogólna. Wprowadzenie do myślenia i działania pedagogicznego w ujęciu systematycznym i historyczno-problemowym. Stępkowski D. (tłum.). Warszawa: Wydawnictwo Naukowe Uniwersytetu Kardynała Stefana Wyszyńskiego.

Bocheński J. M. (1993). Współczesne metody myślenia. Judycki S. (tłum.). Poznań: „W drodze".

Buber M. (1968). Wychowanie. Grygiel S. (tłum.). „Znak”, nr 1, s. 442-461.

Buber M. (1992). Między osobą a osobą. W: tenże. Ja i Ty. Wybór pism filozoficznych. Doktór J. (tłum.). Warszawa: Instytut Wydawniczy Pax.

Camus A. (1991). Mit Syzyfa. Guze J. (tłum.). W: tenże. Dwa eseje. Warszawa: Wydawnictwo Krąg.

Diogenes Laertios. (1988). Żywoty i poglady stynnych filozofów. Krońska I., Leśniak K., Olszewski W. (tłum.). Warszawa: Państwowe Wydawnictwo Naukowe.

Gadacz T. (2015). Pięć koncepcji dialogu. „Kwartalnik Pedagogiczny”, 2, s. 75-91. Gara J. (2016). Fenomen egzystencjalnych wymiarów myślenia utopijnego. W: Gromysz J., Włodarczyk R. (red.). Utopia a edukacja, t. 1. Wrocław: Instytut Pedagogiki Uniwersytetu Wrocławskiego. 
Gara J. (2017). Dialogiczny „logos” intersubiektywnego doświadczenia tego, co „pomiędzy”. W: Jankowska D. (red.). Pedagogika dialogu. Emancypacyjny potencjał dialogu. Warszawa: Wydawnictwo Akademii Pedagogiki Specjalnej.

Gara J. (2018a). (Dia)logika doświadczenia edukacyjnego, społecznego i kulturowego. „Studia z Teorii Wychowania”, 2, s. 23-40.

Gara J. (2018b). Heurystyka Znanego i Nieznanego jako egzystencjalny horyzont aksjologii aktów wychowania. W: Cudowska A. (red.). Życie wartościowe w perspektywie aksjologii pedagogicznej. Gdańsk: Wydawnictwo Naukowe Katedra.

Goffman E. (2008). Człowiek $w$ teatrze życia codziennego. Datner-Śpiewak H., Śpiewak P. (tłum.). Warszawa: Wydawnictwo ALETHEIA.

Goffman E. (2012). Rytuał interakcyjny. Szulżycka A. (tłum.). Warszawa: Wydawnictwo Naukowe PWN.

Heschel A. J. (2007). Bóg szukający człowieka. Gorzkowski A. (tłum.). Kraków: Wydawnictwo Esprit.

Kron F. W. (2012). Pedagogika. Kluczowe zagadnienia. Cieślik E. (tłum.). Sopot: Gdańskie Wydawnictwo Psychologiczne.

Legowicz J. (1986). Historia filozofii starożytnej Grecji i Rzymu. Warszawa: Państwowe Wydawnictwo Naukowe.

Levinas E. (2002). Całość i nieskończoność. Esej o zewnętrzności. Kowalska M. (tłum.). Warszawa: Wydawnictwo Naukowe PWN.

Levinas E. (1984). Filozoficzne określenie idei kultury. Dane etnograficzne. „Studia Filozoficzne", 9, s. 25-34.

Levinas E. (1991a). Antyhumanizm a edukacja. W: tenże. Trudna wolność. Kuryś A. (tłum.). Gdynia: Wydawnictwo Atext.

Levinas E. (1991b). O hebrajski humanizm. W: tenże. Trudna wolność. Kuryś A. (tłum.). Gdynia: Wydawnictwo Atext.

Levinas E. (2008). Odkrywając egzystencję z Husserlem i Heideggerem. Sowa E. (tłum.). Warszawa: Wydawnictwo IFiS PAN.

Machiavelli N. (1987). Książe. Nanke C. (tłum.). W: tenże. Książe, Rozważania nad pierwszym dziesięcioksięgiem historii Rzymu Liwiusza. Warszawa: Państwowy Instytut Wydawniczy.

Ortega y Gasset J. (1995). Bunt mas. Niklewicz P. (tłum.). Warszawa: Muza SA.

Parmenides (1992). O prawdzie i mniemaniu. W: W kręgu przedsokratyków. Jaworski W. (wyb.). Kraków: Wydawnictwo „Miniatura”.

Rogóż D. (2011). Anty-Odyseja podmiotu. Antropologia Emmanuela Levinasa. „Kwartalnik Filozoficzny”, 1, s. 117-129.

Rosenzweig F. (1998). Gwiazda Zbawienia. Gadacz T. (tłum.). Kraków: Wydawnictwo "Znak”.

Rybák D. (2014). The Educational Aspect of Phenomenological Reduction, „Kultura i Wychowanie", 7 (1), s. 42-50.

Rybák D. (2016). Some remarks regarding the importance of Husserl's phenomenology today, „Forum Pedagogiczne”, 2, cz. 1, s. 329-335. 
Rybák D. (2017). Belief and knowing. W: Hogenová, A., Pelcová N., Rybák D. (red.), Contingency in the Education, Art and Sport: international multidisciplinary conference. Prague: Univerzita Karlova v Praze, Pedagogická fakulta.

Skarga B. (1992). Filozofia różnicy. „Przegląd Filozoficzny”, 1, s. 47-64.

Smart B. (1998). Postmodernizm, Wasilewski M. (tłum.). Poznań: Zysk i S-ka Wydawnictwo s.c.

Szacki J. (2002). Historia myśli socjologicznej. Warszawa: Wydawnictwo Naukowe PWN.

Szestow L. (2009). Ateny i Jerozolima. Wodziński C. (tłum.). Kraków: Wydawnictwo "Znak".

Tischner J. (2002). Myślenie według wartości. Kraków: Wydawnictwo „Znak”.

Glinkowski Witold P. (2016). Codzienność i niecodzienność spotkania - dialogika Martina Bubera wobec relacji między wychowawca i wychowankiem. Intuicje pedagogiczne. „Nauki o Wychowaniu. Studia Interdysyplinarne”, 1, s. 38-50.

\title{
BETWEEN IDEALIZATION AND MYSTIFICATION: A PEDAGOGICAL CASE OF DIALOGICAL QUESTIONS AND ANSWERS
}

\begin{abstract}
The problem discussed in this article is presented in the context of five basic ways in which the issue of dialogue is perceived. According to the adopted model, dialogue is an act of meeting, and its key medium of interpersonal relations, including pedagogical relations, is the phenomenon of initiating and responding. Dialogue understood in this way arises from specific assumptions about man. According to them, man as an individual is not only a separate world, but also creates separate worlds. Therefore, dialogue becomes possible only between subjects who mutually recognise their distinctiveness and make a genuine effort to go beyond the other person. Real dialogue must also be clearly distinguished from various negative states of affairs, which are the anti-patterns of dialogical initiating and responding. That is why, the inclusion of arguments and attitudes contrary to the arguments and attitudes of dialogue allows for a better understanding of the constructive meaning and uncommonness of the phenomenon of dialogue.
\end{abstract}

Keywords: philosophy of dialogue; philosophy of education; dialogics of education; dialogue as a meeting; pedagogical relations; negative states of things.

Jarosław Gara - doktor habilitowany, profesor nadzwyczajny Akademii Pedagogiki Specjalnej. Wybrane monografie: Pedagogiczne implikacje filozofii dialogu (2008); Od filozoficznych podstaw wychowania do ejdetycznej filozofii wychowania (2009). Adres do korespondencji: APS, ul. Szczęśliwicka 40, 02-353 Warszawa. Adres e-mailowy: jgara@ aps.edu.pl. 